\title{
Assessing Attractiveness in Online Dating Profiles
}

\author{
Andrew T. Fiore ${ }^{1}$, Lindsay S. Taylor ${ }^{2}$, G.A. Mendelsohn ${ }^{2}$, and Marti Hearst ${ }^{1}$ \\ ${ }^{1}$ School of Information and ${ }^{2}$ Department of Psychology \\ University of California, Berkeley \\ 102 South Hall, Berkeley, Calif. \\ ${ }^{1}\{$ atf, hearst $\} @$ ischool.berkeley.edu, ${ }^{2}\{$ 1staylor, jermend $\} @$ berkeley.edu
}

\begin{abstract}
Online dating systems play a prominent role in the social lives of millions of their users, but little research has considered how users perceive one another through their personal profiles. We examined how users perceive attractiveness in online dating profiles, which provide their first exposure to a potential partner. Participants rated whole profiles and profile components on such qualities as how attractive, extraverted, and genuine and trustworthy they appeared. As past research in the psychology of attraction would suggest, the attractiveness and other qualities of the photograph were the strongest predictors of whole profile attractiveness, but they were not alone: the free-text component also played an important role in predicting overall attractiveness. In turn, numerous other qualities predicted the attractiveness ratings of photos and free-text components, albeit in different ways for men and women. The fixed-choice elements of a profile, however, were unrelated to attractiveness.
\end{abstract}

\section{Author Keywords}

Online personals, attraction, computer-mediated communication, online dating, relationships

\section{ACM Classification Keywords}

H5.3. Group and Organization Interfaces; Asynchronous interaction; Web-based interaction.

\section{INTRODUCTION}

Since the earliest days of mediated communication, people have been looking for love through the wires, the airwaves, or the post. Letters and phone calls are well-known conduits for romance, especially over a distance, but even the telegraph was bent to romantic purposes - Whitty (2007) describes its use for courtship and even for an online wedding ceremony. Telephone dating systems, which allow

Permission to make digital or hard copies of all or part of this work for personal or classroom use is granted without fee provided that copies are not made or distributed for profit or commercial advantage and that copies bear this notice and the full citation on the first page. To copy otherwise, or republish, to post on servers or to redistribute to lists, requires prior specific permission and/or a fee.

CHI 2008, April 5-10, 2008, Florence, Italy.

Copyright 2008 ACM 978-1-60558-011-1/08/04 ..\$5.00 callers to listen to recorded voice advertisements from other users and sometimes connect with them live, have been around for decades, and even today their television advertisements pepper late-night programming. Computer matching services, which purport to identify compatible singles from their pool of members, existed well before the emergence of the Internet; they even feature prominently in a film from the 1970s, the classic dark comedy Harold and Maude, in which Harold's mother enrolls him in the National Computer Dating Service.

Today, we have a variety of richer means of mediated communication. Among these, online dating systems now claim a prominent role in the social lives of millions of users. US News and World Report claimed that in August 2003 alone, 40 million unique users visited online dating Web sites (Mulrine 2003); the Pew Internet and American Life Project estimates that about 7 million American adults have gone on a date with someone they met through online personal advertisements (Madden and Lenhart 2006).

Gauging one's attraction to a potential partner before investing the time, effort, and emotional energy in a faceto-face meeting is a central goal of online daters, yet few studies have addressed how attractiveness is judged in online dating. We designed this study to examine how users evaluate the attractiveness of an online dating profile as a whole from its qualities and the qualities of its components.

\section{COMPUTER-MEDIATED SOCIAL INTERACTION}

Early theories of online interaction contended that communication in lean media - those that convey few different types of information and do so slowly (Daft and Lengel 1986) - precludes the formation of substantial relationships because of a dearth of social cues (Sproull and Kiesler 1986) and the absence of "social presence" (Short et al. 1976). But by the mid-1990s, some researchers (Lea and Spears 1995; Parks and Floyd 1996) began to suggest that a relative scarcity of social cues might not be as detrimental as the earlier work claimed, and that it might in fact aid the formation of interpersonal connections under some circumstances.

A series of studies by Walther and colleagues lent support to this view. Walther's (1992) theory of Social Information Processing contends that people make inferences about others in social situations based on any available cues, 
however scant. His notion of "hyperpersonal" interaction (Walther 1996; Walther et al. 2001) goes a step farther — it suggests that people communicating in lean media, where cues from others are limited in scope and perhaps slow to arrive, might form even higher levels of affinity for one another than they would face-to-face. This results, Walther argues, from a tendency to fill in the blanks optimistically when faced with limited information about a person. Other studies also show evidence of greater affinity in cueconstrained contexts. McKenna and colleagues (2002) found that pairs of college students in a laboratory study liked each other better when they met in synchronous, text-only chat than when they met face-to-face. Online gamers rating potential opponents in Riegelsberger et al.'s (2006) study found text-only profiles more appealing than photo profiles, which garnered a greater number of highly negative responses. The researchers suggest that photo profiles allowed users better to "filter out" undesirable opponents.

\section{Self-presentation and Interpersonal Perception}

Goffman (1957) describes the process of self-presentation as a kind of performance. He distinguishes between the cues we "give" intentionally, as part of the deliberate performance, and those we "give off" unintentionally. Building on these notions and the concept of signaling from biology, Donath (1998; forthcoming) portrays the online performance of self as a series of signals we attempt to give in order to convey a particular impression to others. Everything from the user name (or "handle") to the use of language or the choice of a photograph can signal certain qualities in online interaction; some signals "give" intended meaning while simultaneously "giving off" additional unintended information.

Face-to-face interaction is a rich medium - that is, it provides multiple channels of communication (e.g., words, tone of voice, facial expression, gesture) and immediate feedback (Daft and Lengel 1986). In a face-to-face context, in addition to information conveyed intentionally, cues given off by accident, perhaps through body language, a fleeting expression, or an unbidden change in intonation, also provide a great deal of information about other people. Online, however, cues are considerably more limited, and users have more control over the information they convey. Despite the paucity of cues, personal qualities are still conveyed in online environments. Gosling and colleagues (2007) found that observers' ratings of personality traits based on Facebook profiles ${ }^{1}$ correlated (average $r=0.23$ ) with self-reports and friends' reports of the personality traits of the profile owners. The correlation was strongest for extraversion $(r=0.46)$.

1 Facebook, a social networking Web site, has personal profiles that share many features with online dating profiles but differ in that they are not intended for romantic purposes, and they feature "friends" with whom the user has indicated a social relationship.

\section{ATTRACTIVENESS IN ONLINE DATING PROFILES}

Although online dating users are limited in the types of cues available for self-presentation, they are able to spend time creating and revising their profiles in order to put their best foot forward. That is, they are able to tailor their selfpresentations online in ways they cannot face-to-face.

Users writing their profiles have competing motivations first, to present themselves as attractively as possible, in order to draw the attention of potential dates, and second, to present themselves accurately, so that people who are attracted to them online will still find them attractive when they eventually meet. Fiore and Donath (2004) suggest that online dating users might consider a certain amount of exaggeration necessary if they perceive, as per the popular conception, that everyone else is exaggerating — then they must exaggerate as well just to maintain equal footing with competitors. Indeed, Hancock and colleagues (2007) found that small exaggerations about height, weight, and age in online dating profiles were common.

Since users can self-present selectively (or aspirationally or deceptively) in their online dating profiles, it is difficult for viewers of the profile to be certain that they have an accurate picture of what another user is like in person. If the purpose of online dating were to find partners with whom to interact online only, this would pose no problem - the online relationship would be the end goal. But when the goal is to commence a face-to-face relationship, it can be difficult to discern whom one will find attractive in person.

\section{Assessing Attractiveness}

Historically, theories of interpersonal attraction and interpersonal judgments have emphasized the importance of physical attributes over other factors such as personality and intelligence (e.g., Dion et al. 1972; Walster et al. 1966). Accordingly, online dating sites often urge their users to post photos of themselves to increase the chances that potential dates will contact them. Indeed, $85 \%$ of interviewees in a study of Australian online dating users said they would not contact someone without a photo on his or her profile (Whitty and Carr 2006). Thus, it is possible that the attractiveness of one's photo is the sole, or at least the strongest, predictor of the appeal of one's online dating profile as a whole. At the same time, however, the bulk of the typical site's profile is devoted to describing one's personal characteristics and one's ideal match, although research has not demonstrated that this information contributes to one's attractiveness to potential partners.

Only a few studies so far have considered how users judge attractiveness online generally or in online dating in particular. Ellison and colleagues (2006) describe the strategies employed by online dating users to interpret the self-presentations of others. Primarily, the participants they interviewed made substantial inferences from small cues, lending support to Walther's (1992) theory of Social Information Processing. For example, one woman felt that 
people who were sitting down in their online dating profile photos were trying to disguise that they were overweight. Perhaps needless to say, in her own photo, she was standing (Ellison et al. 2006).

Norton, Frost, and Ariely (2007) found that even though online dating users believe they will like people better when they have more information about them, in fact more information leads to less liking, perhaps because it helps us better to assess incompatibility. But when we're presented with a highly compatible person, more information allows us to be more certain that we will like him or her. Thus, an online dating profile with a lot of information might attract fewer - but potentially more compatible - suitors.

Fiore and Donath (2005) used the number of messages online daters received as a measure of attractiveness and found that men received more messages when they were older, more educated, and had higher levels of self-reported attractiveness (which might be something more like selfesteem). Women received more messages when they did not describe themselves as "heavy," had higher levels of self-reported attractiveness, and posted a photo on their profiles. These results roughly correspond to what we would expect from past social psychological research.

Although this latter study comes closest, none of the aforementioned studies speaks directly to our research question: What qualities of online dating profiles and their components predict attractiveness?

\section{ONLINE DATING SYSTEMS}

Broadly speaking, Web-based online dating systems include the following (Fiore and Donath 2004):

- Personal profiles for each user, which include demographic and other fixed-choice responses, freetext responses to prompts, and, optionally, one or more photographs.

- Searching and/or matching mechanisms so that users can find potential dates from among the thousands of profiles on a typical system.

- Some means of private communication that permits users to contact potential dates within the closed online dating system without disclosing an email address, phone number, or identifying information. This usually means a private mail system, but it sometimes also includes instant messaging or the ability to send "winks" or some other contentless token of interest.

- Optionally, other forms of self-description: for example, the results of a personality test, or audio and video clips uploaded by the user.

\section{METHOD}

In this study, we selected 50 online dating profiles from the Yahoo! Personals Web site, comprising five men and five women between 20 and 30 years of age from each of five U.S. cities - Atlanta, Boston, San Diego, Seattle, and St.
Louis - chosen to represent different regions of the country. To gather five profiles of each gender in each city, we searched for profiles with photos meeting the appropriate criteria - e.g., women in Seattle - and randomly chose one profile from the 10 displayed on each of the first five pages of the search results. The search results were approximately but not strictly ordered by recency of activity, so the profiles we captured belonged to users who had logged in recently.

As described above, these profiles consist of several components. First, the fixed-choice portion contains a series of multiple-choice questions with pre-set responses, including demographics, such as age, gender, race, and religion, and preferences, such as smoking and drinking habits, favorite activities, and interests. Not all profiles included responses to every fixed-choice item. Next, the free-text section allows users to describe themselves and the partner they seek in their own words; these sections range from a few words to many paragraphs. Finally, each profile includes a photo uploaded by the profile's author. Some profiles had more than one photo; in these cases we used only the primary one. Yahoo! Personals crops the primary photos, so all were headshots.

We saved images of these profiles exactly as they appeared in the Web browser and then subdivided them with Adobe Photoshop into these three components: the free-text part of the profile, the primary photo, and the fixed-choice part of the profile (Figure 1). With 50 profiles, this process yielded a total of 200 images, including images of whole profiles.

Using a custom-built Web application that identified participants only by an anonymous number, we asked participants their own sex and the sex of the people they usually date. Our software then presented each participant with a randomly selected series of profile components (free text, fixed choice, and photo) and whole profiles drawn from the 25 profiles of the appropriate gender. With four images generated from each profile, each participant could rate up to 100 images.

The software (Figure 2) asked participants to rate whole profiles and profile components using a five-point Likerttype scale from 0 (not at all) to 4 (very much) on the following dimensions:
- Attractive
- Genuine, trustworthy
- Masculine
- Feminine
- Warm, kind
- Self-esteem
- Extraverted
- Self-centered

The order of these dimensions was randomized with each profile or profile component for each participant so as to avoid order effects. Participants always had the option to 


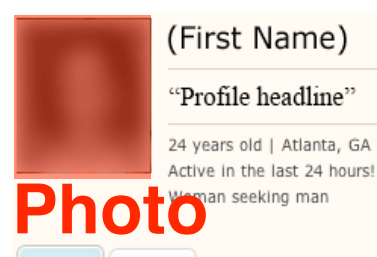

Details Photos

\begin{tabular}{|c|c|c|}
\hline \multicolumn{3}{|c|}{ Quick View [ customize ] } \\
\hline & (First name) & Her ideal Man \\
\hline \multicolumn{3}{|l|}{ Ethnicity } \\
\hline \multicolumn{3}{|l|}{ Height } \\
\hline Smoking & Doesn't smoke & Any \\
\hline Has Kids & No & Any \\
\hline
\end{tabular}

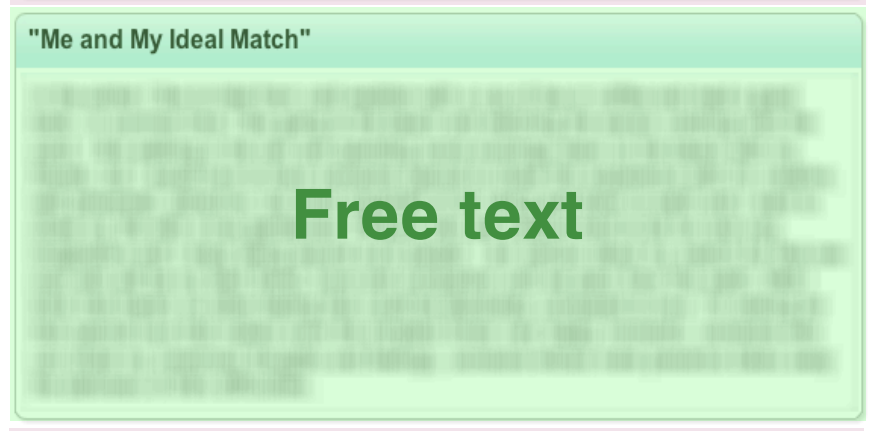

\begin{tabular}{|lll|}
\hline Appearance & & \\
\hline Age & (First name) & Her ideal Man \\
\hline Ethnicity & 24 years old & 18 to 34 \\
\hline Height & Caucasian (white) & Any \\
\hline Body Type & $5^{\prime} 5^{\prime \prime}$ & Any \\
\hline Eye Color & Slim & Any \\
\hline Hair Color & Green & Any \\
\hline
\end{tabular}

\section{Lifestyle}

\begin{tabular}{lll} 
Smoking & (First name) & Her ideal Man \\
\hline Alcohol & Doesn't smoke & Any \\
Education & Doesn't drink & Any \\
Employment Status & Unemployed & Any \\
\hline Occupation & I'll tell you later & Any \\
\hline Income Level & I'll tell you later & Any \\
\hline
\end{tabular}

\begin{tabular}{lll|}
\hline Home Life & (First name) \\
Location & Atlanta, Georgia & $\begin{array}{l}\text { Her ideal Man } \\
\text { Within 250 miles of Atlanta, } \\
\text { Georgia }\end{array}$ \\
\hline Marital Status & Single - never married & Any \\
\hline Living Situation & Alone & Any \\
\hline Has Kids & No & Any \\
\hline Wants (more) Kids & Yes & Any \\
\hline Religion & Christian & Any \\
\hline Attends Services & Weekly & Any \\
\hline Languages Spoken & English & Any \\
\hline
\end{tabular}

\begin{tabular}{|l|l|l|}
\hline Personality & $\begin{array}{l}\text { (First name) } \\
\text { Dancing, Movies, Listening to } \\
\text { Music, Reading, Theater, Cooking, } \\
\text { Playing Music }\end{array}$ \\
\hline Astrological Sign & $\begin{array}{l}\text { Taurus (April 20 - May 20) } \\
\text { Political Views }\end{array}$ & Friendly \\
\hline Sense of Humor & Comic Relief & Any \\
\hline Social Setting & Dramas, Movies, Documentaries Any \\
\hline TV Watching Habits & Ano Answer & Any \\
\hline Personality Type & No Answer & Any \\
\hline Love Style & & Any \\
\hline
\end{tabular}

Figure 1. (Left and above) One of the 50 online dating profiles, obfuscated to protect the privacy of the profile author.

The entire figure represents the whole profile; the three constituent pieces are highlighted. The fixed-choice piece is stitched together from the noncontiguous parts with Photoshop. (The profile appears online and in our study software as one long Web page, but it is broken up here to fit on the page.)

Figure 2. (Above) The Web interface participants used to rate profiles and profile pieces. Radio buttons capture the participant's ratings and confidence levels. The profile or profile component to be rated appears to the right on screen. 
choose "Prefer not to answer" for any of the dimensions. For each dimension for which they did provide a rating, the software prompted participants to indicate how confident they were about their response using a three-point Likerttype scale where 1 denoted low confidence in their rating and 3 denoted high confidence. We included the confidence ratings so that we could distinguish between certain and uncertain ratings and so users would feel comfortable giving ratings when they were uncertain instead of choosing "Prefer not to answer."

At the start of the session, the software presented each participant with one image (whole profile, photo, free text, or fixed choice) from each of the 25 profiles, with both the order of the profiles and the choice among the four types of image randomized on the fly for each participant. If the participant completed ratings of these first 25 profiles and profile components, which most did, the software then began to show them randomly ordered new images from profiles from which they had already seen an image. Even though most participants rated more than one image from each profile, they never rated the exact same component or whole profile more than once. We marked those ratings of images from profiles from which the participant had previously rated another image so that we could analyze them separately, in case previous exposure to another image of the same profile tainted the ratings of a later image.

Participants rated as many whole profiles and profile components as they could in the 50-minute period. If they rated all 100 available to them, the software ended their session early to ensure that no whole profile or component was rated more than once. At the end of the period, participants provided demographic information and ratings of their own attractiveness and self-esteem on a 0 to 4 scale, and they were debriefed.

\section{Participants}

We recruited participants from a pool consisting of members of the university community, primarily students and staff, who were paid for their participation. Our sample consisted of 65 heterosexual participants, including 41 women (63\%), 23 men (35\%), and one who preferred not to give a gender $(2 \%)$. The participants were between 19 and 25 years old, with a mean and median age of 21 . The majority (66\%) were Asian, and 20\% were white. The remaining participants were of various ethnicities or declined to state an ethnicity. The participants' mean selfreported attractiveness was 2.8 (median 3 ) on a 0 to 4 scale; their mean self-reported self-esteem was 2.7 (median 3) on the same scale.

\section{Profiles}

The mean age of the people in our set of 50 online dating profiles was 25.7 years (median 26). Half were men and half were women. Most were Caucasian (56\%); the rest were African-American (16\%), Asian (4\%), East Indian (2\%), Hispanic/Latino (10\%), Middle Eastern (2\%), Pacific
Islander $(4 \%)$, or another ethnicity $(2 \%)$. Two profiles did not report an ethnicity.

The free-text components of the profiles ranged from 29 to 793 words long $($ mean $=168$; median $=114)$. Analysis with the Linguistic Inquiry and Word Count software (Pennebaker and Francis 1996) showed that profile authors used more positive emotion words $(7.5 \%$ of the words in the free-text component on average) than negative emotion words $(0.9 \%$ on average $), t(60.4)=12.8, p<.001$. Women used significantly more positive emotion words than men $(8.6 \%$ vs. $6.3 \%$ of words; $t(40.8)=2.42, p<.05)$ and more self-references such as "I," "me," and "my" (9.5\% vs. $7.5 \% ; t(45.7)=2.34, p<.05)$.

\section{RESULTS}

Each whole profile and profile component was rated by multiple participants on each of the eight dimensions, for a total of 29,120 ratings. A preliminary analysis showed that some ratings of Profile 33 were outliers; upon investigation, we found that the woman in this profile mentioned that she was transsexual, though this was evident only in her freetext response, not in her photo or fixed-choice response. We excluded responses to Profile 33 and its components from further analysis. The perception of transsexual individuals online is worthy of exploration, but having just one representative in this set of profiles was insufficient for analysis.

\section{Standardization of the responses}

In rating profiles and profile components, participants might reasonably differ in how they interpret and use the 0 to 4 scale. For example, Participant A might assign only $3 \mathrm{~s}$ and $4 \mathrm{~s}$, so even though 3 is a moderately high rating on the scale, for Participant $A$ it is low. On the other hand, Participant B might assign no $3 \mathrm{~s}$ or $4 \mathrm{~s}$ and many $1 \mathrm{~s}$ and $2 \mathrm{~s}$, so for this participant, 2 would be a high rating. The same participant's interpretation of the scale might even differ from one dimension to another. Since the qualities we are studying are subjective, we are primarily interested in the relative magnitude of a rating. That is, we want to know which ratings are high and low for a given participant, for a given quality even if they are not high or low on the scale in absolute terms.

To achieve this, we employed a type of standardization called "ipsatization" (Cunningham 1977). First, we calculated the mean and standard deviation of the ratings for each dimension for each participant - that is, we calculated 8 dimensions $\times 65$ participants $=520$ means and SDs. Then we standardized each rating by subtracting the mean and dividing by the SD associated with the appropriate participant and dimension. For example, we found Participant A's mean rating and its standard deviation on the extraversion dimension, then standardized all of A's extraversion ratings with those values. All analyses were performed with these ipsatized ratings. 


\section{Repetition Effects}

We were uncertain whether participants' ratings of a profile component or whole profile would differ if they had previously rated another component (or the whole) of the same profile. (Note that although participants did rate multiple components from each profile, they never rated the exact same image more than once.) After data collection was complete, we checked whether those components rated after a participant had already seen other components from the same profile were rated differently from components of profiles the participant had never seen before. Analyses indicated that they did not differ meaningfully, so for the rest of our analyses, we used the complete set of ratings.

\section{Regression models to predict attractiveness}

We built ordinary least squares regression models to do the following:

1. Predict the attractiveness of whole profiles from ratings of the other seven dimensions of whole profiles.

2. Predict the attractiveness of whole profiles from the attractiveness and other qualities of their components (free text, fixed choice, and photo).

3. Predict the attractiveness of the profile components from their ratings on the other seven dimensions.

Because not every participant rated each component of each profile, we averaged responses across participants to find the mean ratings of each whole profile and each component for each of the eight dimensions. We consider these to be point estimates of the true score of each profile or profile component on each of the eight dimensions. Thus, these regression models are based on various combinations of these 1600 mean ratings $(50$ profiles $\times 4$ images $\times 8$ rating dimensions) distilled from more than 29,000 raw responses. In the following sections, we report standardized estimates of the OLS regression coefficients with associated $t$ statistics and $p$ values.

\section{Predicting attractiveness of whole profiles}

We begin our analysis by considering the association between whole-profile attractiveness and the other seven dimensions on which whole profiles were rated. Then we examine how the attractiveness and other qualities of profile components predict the attractiveness of whole profiles.

\section{Attractiveness and other qualities of whole profiles}

For men's whole profiles (Table 1, column 1), high masculinity ratings predicted high overall attractiveness $(b$ $=.42, t(18)=2.40, p<.05)$. None of the other qualities of whole profiles was a significant predictor of attractiveness.

For women's whole profiles (Table 1, column 2), high extraversion ratings predicted high overall attractiveness $(b$ $=.73, t(17)=4.01, p<.001)$. Low masculinity scores were associated with higher attractiveness, but this result was of borderline significance $(b=-.31, t(17)=2.09, p<.06)$.

Whole-profile attractiveness and component attractiveness Next, we examined the association between whole-profile attractiveness and the attractiveness of the profile components (Table 2). For both men's and women's profiles, photo attractiveness was by far the strongest and most significant predictor of whole-profile attractiveness, $b$ $=.87, t(21)=8.46, p<.001$ for women's profiles and $b=$ $.72, t(22)=6.77, p<.001$ for men's profiles. The attractiveness of the free-text components was also a significant predictor of whole-profile attractiveness for women's profiles $(b=.22, t(21)=2.14, p<.05)$ and a
Whole-profile attractiveness

Photo attractiveness

Free-text attractiveness

\begin{tabular}{|c|c|c|c|c|c|c|}
\hline Dimension & MEN & WOMEN & MEN & WOMEN & MEN & WOMEN \\
\hline Genuine/trustworthy & $.38(.32)$ & $.08(.10)$ & $1.62(.35)^{\star \star \star}$ & $.15(.25)$ & $.70(.15)^{\star \star \star}$ & $.19(.33)$ \\
\hline Masculine & $.42(.17)^{*}$ & $-.31(.15)^{\dagger}$ & $.24(.20)$ & $-.49(.13)^{\star \star}$ & $.29(.14)^{\dagger}$ & $.06(.30)$ \\
\hline Feminine & $.22(.18)$ & $.28(.17)$ & $.46(.18)^{*}$ & $.34(.17)^{\dagger}$ & $.37(.14)^{*}$ & $.30(.36)$ \\
\hline Warm/kind & $.16(.31)$ & $-.05(.16)$ & $-1.27(.39)^{\star *}$ & $-.51(.30)$ & $-.30(.24)$ & $.13(.34)$ \\
\hline Self-esteem & $.25(.22)$ & $-.16(.17)$ & $-.20(.27)$ & $.51(.19)^{*}$ & $-.05(.18)$ & $.15(.30)$ \\
\hline Extraverted & $-.10(.21)$ & $.73(.18)^{\star \star \star}$ & $.70(.26)^{*}$ & $.07(.16)$ & $.57(.23)^{*}$ & $.23(.23)$ \\
\hline Self-centered & $.19(.20)$ & $-.01(.16)$ & $-.04(.20)$ & $-.43(.23)^{\dagger}$ & $-.09(.15)$ & $-.11(.38)$ \\
\hline \multirow[t]{2}{*}{ Adjusted $\mathbf{R}^{2}$} & .75 & .83 & .76 & .74 & .86 & .07 \\
\hline & & $p<.001$ & ${ }^{\star} p<.05$ & ${ }^{\dagger} p<.1$ & & \\
\hline
\end{tabular}

Table 1. Standardized regression models to predict attractiveness ratings of whole profiles, photo components, and free-text components from ratings of these entities on the other seven dimensions. Coefficient estimates with standard errors in parentheses. 


\begin{tabular}{lcc} 
Covariate & $\begin{array}{c}\text { Men's } \\
\text { whole-profile } \\
\text { attractiveness }\end{array}$ & $\begin{array}{c}\text { Women's } \\
\text { whole-profile } \\
\text { attractiveness }\end{array}$ \\
\hline Photo attr. & $.72(.11)^{\star \star *}$ & $.87(.10){ }^{* \star *}$ \\
Free-text attr. & $.23(.13)^{+}$ & $.22(.10)^{*}$ \\
Fixed-choice attr. & $.09(.11)$ & $-.05(.10)$ \\
\hline Adjusted $\mathbf{R}^{2}$ & .82 & .77 \\
${ }^{* \star *} p<.001$ & ${ }^{* *} p<.01{ }^{*} p<.05$ & ${ }^{\dagger} p<.1$
\end{tabular}

Table 2. Standardized regression models to predict wholeprofile attractiveness ratings from the attractiveness ratings of the profiles' components. We report coefficient estimates with standard errors in parentheses.

marginally significant predictor for men's profiles $(b=.23$, $t(22)=1.83, p<.09)$. The attractiveness of fixed-choice components was not significantly associated with the attractiveness of whole profiles for men or women.

We also built regression models to predict the attractiveness of men's and women's profiles with the predictors above plus the interaction terms photo $\times$ free-text, photo $\times$ fixedchoice, free-text $\times$ fixed-choice, and the three-way interaction photo $x$ free-text $x$ fixed-response. In these models, for men's and women's profiles, main effects of photo and free-text attractiveness remained significant, confirming the results reported above. None of the two-way interaction terms was significant. However, for men's profiles only, the three-way interaction was significant, $b=$ $-.36, t(18)=2.64, p<.05$. Adjusted $\mathrm{R}^{2}$ rose only slightly from the model without interactions, from .82 to .86 . Further examination of the three-way interaction effect revealed that under this model, for a male profile to be rated

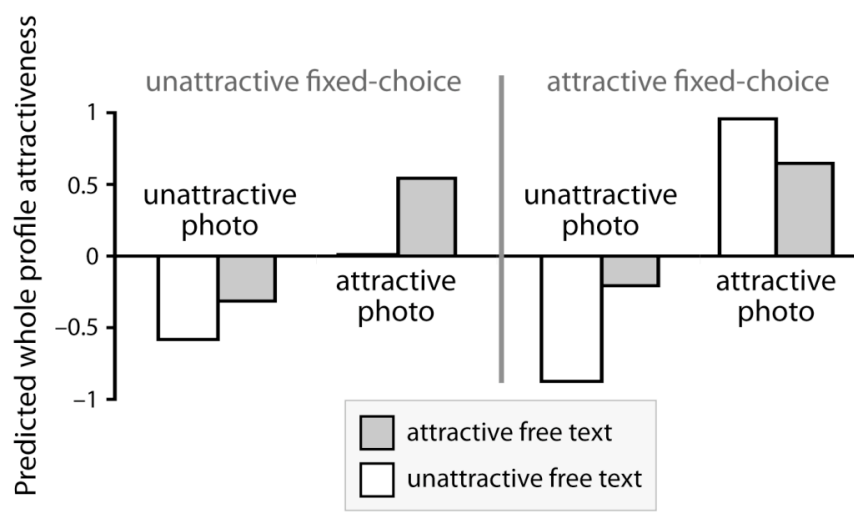

Figure 3. The three-way interaction between attractiveness of the photo component, attractiveness of the free-text component, and attractiveness of the fixed-choice component in predicting the overall attractiveness of men's whole profiles. above average in attractiveness, at least two of the three components must be seen as attractive, and one of those components must be the photo. As can be seen in Figure 3, when the photo is unattractive, the predicted whole profile attractiveness is below 0 (i.e., below the mean, since the variables are standardized) regardless of whether the other components are seen as attractive or not. However, when the photo and at least one other component are attractive, the whole profile is seen as above average in attractiveness.

In short, this first set of analyses points to the importance of having both an attractive photo and an attractive free-text component in order to have an attractive profile. Next we address how the qualities of the constituent pieces of a profile relate to the attractiveness of the whole.

Whole-profile attractiveness and other component qualities The analyses reported in the previous section indicate that the photo and free-text components of the profiles contributed to whole-profile attractiveness. To further examine which particular aspects of the photo and free-text profile components predict the attractiveness of the whole profile, we next regressed whole-profile attractiveness on the ratings of the other seven rated dimensions - that is, besides attractiveness — for the photo and free-text components in two separate regressions. As above, we did this separately for men's and women's profiles.

None of the qualities of the free-text components besides attractiveness significantly predicted whole-profile attractiveness for women's or men's profiles. Several interesting findings emerged with respect to the photos, however. For women's profiles, the whole profiles were seen as more attractive when the women in the photos were seen as having higher self-esteem, $b=.45, t(17)=2.10, p<$ .06 , and being relatively more feminine, $b=.39, t(17)=$ $1.97, p<.07$, and less masculine, $b=-.32, t(17)=2.12, p$ $<.05$. Two of these three effects, though, were only marginally significant; adjusted $\mathrm{R}^{2}$ for this model was .66 .

Men's whole profiles were seen as significantly more attractive when their photos were rated as being more genuine and trustworthy, $b=1.72, t(18)=3.44, p<.01$, and relatively less warm and kind, $b=-1.45, t(18)=2.59$, $p<.05$. Adjusted $\mathrm{R}^{2}$ for this model was .50 .

\section{Predicting attractiveness of profile components}

As we have seen, the attractiveness of profile components, in particular free text and photos, predicts the attractiveness of whole profiles. Now we examine what predicts the attractiveness of the components themselves.

\section{Attractiveness of photos}

Men's photos (Table 1, column 3) were rated as much more attractive when raters perceived them as genuine and trustworthy $(b=1.62, t(18)=4.68, p<.001)$ and when they saw them as not warm and kind $(b=-1.27, t(18)=$ $3.27, p<.01)$, the same features of photos that predicted whole-profile attractiveness. Men's photos were also seen 
as somewhat more attractive when they appeared more extraverted $(b=.70, t(18)=2.68, p<.05)$ and feminine $(b$ $=.46, t(18)=2.49, p<.05)$.

Paralleling the findings for whole-profile attractiveness, women's photos (Table 1, column 4) were rated as more attractive when they were perceived as more feminine $(b=$ $.34, t(17)=1.98, p<0.07$, marginally significant), less masculine $(b=-.49, t(17)=3.73, p<0.01)$ and higher on self-esteem $(b=.51, t(17)=2.69, p<0.05)$. Additionally, lower ratings on self-centeredness were associated with the attractiveness of women's photos, but only at a marginally significant level $(b=-.43, t(17)=1.86, p<0.08)$.

\section{Attractiveness of free-text profile components}

Men's open-ended, free-text profile components (Table 1, column 5) were perceived as more attractive when they were rated as genuine and trustworthy $(b=.70, t(18)=$ 4.56, $p<.001)$ and extraverted $(b=.57, t(18)=2.49, p<$ $0.05)$. High ratings on masculinity and femininity were both associated with attractiveness as well, $b=.37, t(18)=2.63$, $p<0.05$ for femininity and a marginally significant $b=.29$, $t(18)=2.03, p<0.06$ for masculinity. Attractiveness of the free-text component was not associated with its length in words or the percentage of positive emotion words, negative emotion words, or self-references.

In ratings of women's free-text profile components (Table 1, column 6), attractiveness was not significantly associated with any of the other dimensions.

\section{Attractiveness of fixed-choice profile components}

Attractiveness of the fixed-choice profile components was not significantly associated with any of the other rated dimensions for men's or women's profiles.

\section{Confidence ratings}

The median confidence level for all the ratings of all dimensions was 2 (mean 2.1) on the three-point scale from 1 to 3 . Indeed, participants gave more than $70 \%$ of the ratings a confidence level of 2 . This suggests that they were moderately confident in their ratings most of the time. Ratings of most of the eight dimensions were higher when participants were more confident in their assessments. Furthermore, participants were more confident in their ratings of the dimensions of whole profiles (mean confidence 2.21) than in their ratings of any of the profile components, as we might expect, since whole profiles include all of the information in their components. They were also more confident in ratings of free-text components than in ratings of photos. They were least confident in their ratings of fixed-choice components (mean confidence 2.05). All these differences were highly significant, $p<.0001$.

\section{Participant attractiveness and self-esteem}

There was no correlation between participants' selfreported attractiveness or self-esteem and any of the ratings of profiles or profile components. A small correlation was evident between self-reported attractiveness and the confidence participants indicated in their responses $(r=.13$, $p<.001)$.

\section{DISCUSSION}

As might be expected from prior research on interpersonal attraction and mediated communication, our analysis underscores the importance of having an attractive photo in order for one's profile to be judged attractive as a whole. However, attractiveness in photos is not as simple as having a strong jaw-line or a symmetrical face; in fact, participants associated many other qualities with attractiveness. Photos of men appeared attractive when they looked genuine and trustworthy, extraverted, feminine, and not too warm and kind. Photos of women were rated as attractive when they appeared more feminine, less masculine, higher in selfesteem, and lower in self-centeredness.

Importantly, though, photos are not the whole story behind attractiveness. Levine (2000) claims: "The beauty of the virtual medium is that flirting is based on words, charm, and seduction, not physical attraction and cues." In terms of the present data, this is an overstatement - appearance does matter - but it is clear that the attractiveness of freetext responses also plays a role in the attractiveness of the whole profile.

Fixed-choice responses, on the other hand, appear to have only a minimal association with how attractive the whole profile appears, though we believe it is possible that online daters use this section to rule out those profiles with "deal breakers" - qualities that they cannot tolerate in a partner. The fact that attractiveness ratings of fixed-choice components were significantly lower when participants were more confident in their ratings lends support to this interpretation.

Altogether, then, for men hoping to attract women online, it appears especially important to present oneself as genuine and trustworthy, as well as extraverted. Additionally, there was an interesting relationship between femininity and attractiveness. Men's photos and free-text components were rated as more attractive when they were seen as more feminine. At the same time, though, the whole profiles were rated as more attractive when they were seen as more masculine. This pattern of results is puzzling. Clearly, the relationship between femininity, associated characteristics like warmth and kindness, and attractiveness in men's profiles is complicated; a follow-up study with more men's profiles would help answer these questions more definitively.

For women hoping to attract men online, the data suggest that they will be seen as most attractive when they appear extraverted and not masculine. Additionally, it helps if one's photo conveys high self-esteem without appearing self-centered.

In our analyses, we found a greater number of significant predictors of attractiveness for men's profiles than for women's profiles, though some of the non-significant 
predictors for women's profiles approached significance. Although this could indicate that the attractiveness of women's profiles is harder to predict from the dimensions we measured, it is more likely that the smaller number of male participants (who rated the women's profiles) than female participants in our study resulted in less reliable data for women's profiles than for men's.

\section{Limitations}

Though we believe the present work offers a richer characterization of attractiveness in online dating profiles than previous work, we recognize some limitations to our findings. First, our participants were disproportionately Asian, whereas the sample of profiles included only a few Asians. Furthermore, our participants were younger than the bulk of the online dating population and younger on average than the people depicted in the profiles. Therefore, it would be wise to replicate this study with broader samples of both raters and profiles.

Second, we recognize that since our participants were not actually going online to seek dates, they might or might not be interested in dating any of the people depicted in the profiles presented to them. This points to an unavoidable ambiguity in the meaning of attractiveness - is the participant rating the attractiveness of a profile to himself personally, or according to a general standard (i.e., predicting a consensus judgment)? It is unclear whether the two are separable. We believe that, given the nature of the instructions, participants understood the task to be judging how attractive they found the individual portrayed in a given profile or profile component, just as they were judging how extraverted they found the same individual. They were not asked to indicate whether they thought most people would find the profile attractive or whether they would like to date the person represented in the profile. Each of these approaches is of interest, but for this study, we chose the simple and direct approach of capturing subjective assessments.

Finally, we cannot determine the direction of causation with the associational data from this study. For example, our results indicate that a man's photo that appears to be extraverted will more likely be rated attractive than one that does not appear so, but it is unclear whether appearing extraverted makes a photo more attractive or is merely associated with attractiveness. It is also possible that participants judging a photo attractive assumed other positive qualities (the "halo effect"), thereby inflating the positive association between attractiveness and other valued qualities (cf. Dion et al. 1972). Similarly, a halo effect is one plausible explanation for some of our results about whole profiles. However, not all the socially desirable dimensions correlated positively with attractiveness, which argues against a halo effect as the sole explanation for the findings. It is important to note, too, that our study design makes the halo effect unlikely to have affected ratings of the free-text and fixed-choice profile components.

\section{Future Directions}

Even though psychologists have uncovered commonalities in what people find attractive, romantic attraction remains a highly subjective, personal experience. What one person finds attractive the next might not. Moreover, romantic bonds are usually dyadic and reciprocal, so calculating the "average attractiveness" of an online dating profile is only a first step. Future work would do well to examine the qualities of dyads, not just individuals, that predict mutual attraction, and to consider not just attractiveness but also willingness to meet and engage in a relationship with a particular potential partner.

Also, in this study, we considered only those profiles with photos because of the well-established importance of physical attractiveness in both offline and online settings. However, the relative attractiveness of profiles and profile components in the absence of photos would be interesting to consider. Fiore and Donath (2005) found that the presence of a photo was an important predictor of how many messages an online dating user received, especially for women, but they did not model separately the influence of other components given the presence or absence of a photo. Future work should explore the role of the photo more thoroughly.

\section{CONCLUSION}

Forming impressions of others in computer-mediated communication requires attention to different sets of cues than we might use for the same purpose face-to-face. Online dating systems, combining pseudonymous textual communication with photos and the anticipation of a faceto-face meeting, seem to occupy a middle ground between the physicality of the offline world and the slippery virtuality of the online world. Participants in our study assessed attractiveness accordingly, both confirming the importance of physical attractiveness and also paying heed to qualities of text, the vehicle of self-presentation in so many computer-mediated environments.

\section{ACKNOWLEDGMENTS}

This work was supported in part by NSF HSD-IIS 0624356 and by Microsoft Research. We would also like to thank Coye Cheshire and our anonymous reviewers for their insights and suggestions and the staff of the UC-Berkeley XLab for their assistance.

\section{REFERENCES}

1. Cunningham, W.H., Cunningham, I.C.M., and R.T. Green. "The Ipsative Process to Reduce Response Set Bias." In The Public Opinion Quarterly 41 (3), 1977: pp. 379-384.

2. Daft, R.L., and R.H. Lengel. "Organizational Information Requirements, Media Richness and Structural Design." In Management Science 32 (5), 1986: pp. 554-571. 
3. Dennis, A.R., and S.T. Kinney. "Testing media richness theory in the new media: The effects of cues, feedback, and task equivocality." In Information Systems Research 9 (3), 1998 .

4. Dion, K., Berscheid, E., and E. Walster. (1972). What is Beautiful is Good. In Journal of Personality and Social Psychology 24, pp. 285-290.

5. Donath, J. "Identity and Deception in the Virtual Community." In Smith, M., and P. Kollock (Eds.) Communities in Cyberspace. London: Routledge, 1998.

6. Donath, J. Signals, Truth and Design. Cambridge, Mass.: MIT Press (forthcoming).

7. Ellison, N., Heino, R., and J. Gibbs. "Managing Impressions Online: Self-Presentation Processes in the Online Dating Environment." In Journal of ComputerMediated Communication 11 (2), 2006.

8. Fiore, A.T., and J.S. Donath. "Online Personals: An Overview." In Extended Abstracts of Computer-Human Interaction 2004.

9. Fiore, A.T., and J.S. Donath. "Homophily in Online Dating: When Do You Like Someone Like Yourself?" In Extended Abstracts of Computer-Human Interaction 2005.

10.Goffman, E. (1956) The Presentation of Self in Everyday Life. New York: Doubleday.

11.Gosling, S.D., Gaddis, S., and S. Vazire. (2007) "Personality Impressions Based on Facebook Profiles." International Conference on Weblogs and Social Media 2007, Boulder, Colo.

12.Hancock, J.T., Toma, C., and N. Ellison. "The truth about lying in online dating profiles." In Proc. Computer-Human Interaction 2007.

13.Lea, M., and R. Spears. (1995). "Love at first byte? Building personal relationships over computer networks." In J. T. Wood and S. Duck (Eds.), Understudied relationships: Off the beaten track. Newbury Park, Calif.: Sage.

14.Levine, D. (2000). "Virtual Attraction: What Rocks Your Boat." In CyberPsychology and Behavior 3 (4), pp. 565-573.

15.Madden, M., and A. Lenhart. Online Dating. Pew Internet and American Life Project (2006).

16.McKenna, K.Y.A., Green, A.S., and M.E.J. Gleason. (2002). "Relationship Formation on the Internet: What's the Big Attraction?” In Journal of Social Issues 58 (1), pp. 9-31.

17. Mulrine, A. "Love.com: For better or for worse, the Internet is radically changing the dating scene in America." In U.S. News and World Report, Sept. 29, 2003.
18. Norton, M., Frost, J., \& D. Ariely. (2007). Less is more: The lure of ambiguity, or why familiarity breeds contempt. In Journal of Personality and Social Psychology 92 (1), pp. 97-105.

19.Parks, M.R., and K. Floyd. "Making Friends in Cyberspace." In Journal of Computer-Mediated Communication 1 (4), 1996.

20.Pennebaker, J.W., and M.E. Francis. "Cognitive, Emotional, and Language Processes in Disclosure." In Cognition and Emotion 10 (6), 1996.

21.Riegelsberger, J., Counts, S., Farnham, S.D., and B.C. Philips. "Sounds Good to Me: Effects of Photo and Voice Profiles on Gaming Partner Choice." In Proceedings of Computer-Supported Cooperative Work 2006.

22.Short, J., Williams, E., and B. Christie. (1976). The social psychology of telecommunications. London: Wiley.

23.Sproull, L., and S. Kiesler. (1986). Reducing social context cues: Electronic mail in organizational communication. In Management Science 32: pp. 1492-1512.

24.Walster, E., Aronson, V., Abrahams, D., and L. Rottman. (1966). "Importance of Physical Attractiveness in Dating Behavior." In Journal of Personality and Social Psychology 4, pp. 508-516.

25. Walther, J. B. (1992). Interpersonal effects in computermediated interaction: A relational perspective. Communication Research, 19 (1), 52-91.

26. Walther, J.B. "Computer-mediated communication: Impersonal, interpersonal, and hyperpersonal interaction." In Communication Research 23 (1), 1996: pp. 3-44.

27.Walther, J.B., Slovacek, C., and L.C. Tidwell. "Is a picture worth a thousand words? Photographic images in long term and short term virtual teams." In Communication Research 28 (1), 2001: pp. 105-134.

28. Whitty, M. (2003). "Cyber-Flirting: An Examination of Men's and Women's Flirting Behaviour Both Offline and on the Internet." In Behaviour Change 21 (2), 2004.

29. Whitty, M. (2007). "Love letters: The development of romantic relationships throughout the ages." In Joinson, A., McKenna, K., Postmes, T., and U-D. Reips (Eds.) The Oxford Handbook of Internet Psychology. Oxford, England: Oxford University Press.

30.Whitty, M., and A. Carr. (2006). Cyberspace Romance: The Psychology of Online Relationships. New York: Palgrave Macmillan. 